\title{
Isolated Bronchial Injury: A Diagnostic and Management Challenge
}

Ashwani Kumar Dalal, Usha Rani Dalal*, Virender Saini and Dheeraj Kapoor

Government Medical College and Hospital, Chandigarh, India

*Corresponding author: Usha Rani Dalal, Government Medical College and Hospital, Chandigarh, India, 160030, Tel: + (91)-172-2661154; E-mail: dalalakd@gmail.com

Received date: July 11, 2017; Accepted date: August 22, 2017; Published date: August 27, 2017

Copyright: (C) Dalal AK, et al. This is an open-access article distributed under the terms of the Creative Commons Attribution License, which permits unrestricted use, distribution, and reproduction in any medium, provided the original author and source are credite.

\begin{abstract}
Injuries to the trachea or major bronchi in high-speed motor vehicle accidents are mostly accompanied by fatal pulmonary contusion, vascular injury, abdominal injury, head injury, spine injury, and orthopaedic injury. Isolated major bronchial injury without any other major organ or vascular injury in blunt chest trauma is a rare entity. In most of these cases, the trauma may be trivial but sudden compression of chest leads to isolated tracheo-bronchial disruption. The diagnosis and management approach depends upon the existence and severity of other injuries. Cause of concern in a missed or delayed diagnosis is high mortality due to tension pneumothorax and significant morbidity due to progressive respiratory failure because of continuous major air leaks and/or debilitating chronic complications (persistent pneumothorax, atelectasis, fibrosis, pneumonitis, and empyema). Prompt diagnosis, skilful airway management along with early surgical intervention can greatly reduce the morbidity and mortality. The present retrospective study is over a period of eleven years (2004-2015). The demographic data including the aetiology, clinical features, radiological, bronchoscopic and operative findings were compiled from the records. A total of five cases, all males were diagnosed with major bronchial injuries. One case was diagnosed within $8 \mathrm{~h}$, one was diagnosed after $48 \mathrm{~h}$ and in these cases primary repair was done. In three cases, diagnosis was made after 3 weeks and delayed repair was done. The average hospital stay was 21 days and follow up was 6 months. The clinical presentation and outcome stress the key role of early diagnosis and timely surgical intervention.
\end{abstract}

Keywords: Blunt chest trauma; Isolated bronchial injury; Prompt diagnosis; Early repair

\section{Introduction}

The injuries of major airways in high speed motor vehicle accidents is a relatively uncommon with a reported incidence of $0.03 \%-3 \%$ [1-3]. Besides blunt chest injuries, the presence of associated other multiple injuries (head, facial, spine, abdomen, vascular and orthopaedic) are important determinants of outcome [4,5]. In $25 \%$ of cases, deaths are due to thoracic trauma. The airway injury is mostly fatal and it is reported that a large proportion $(81 \%)$ of the airway injury patients died immediately or before reaching the hospital due to tension pneumothorax [6]. The incidence of trachea-bronchial tree injury is $0.5 \%$ in blunt trauma and $1-2 \%$ in penetrating trauma. Isolated major bronchial injury without any other major organ or vascular injury in blunt chest trauma is rare. Most of injuries due to blunt trauma involve intra-thoracic trachea or main stem bronchi. Diagnosis is delayed in $25-68 \%$ of the patients [7]. Airway injuries may escape diagnosis due to distal intubation done to stabilize the patient with multiple injuries or they may not be clinically suspected initially. A detailed clinical examination must be done for a prompt diagnosis based on the critical symptoms in the patients who arrive alive in the hospital [8]. Diagnostic modalities include clinical, radiological and bronchoscopic examinations. Efficient management of the airway with early surgical repair is the key for excellent recovery. Respiratory failure can occur if diagnosis is missed or delayed. The aim of the present study is to gain an insight into the diverse clinical spectrum of isolated blunt bronchial injuries.

\section{Material and Methods}

A total of 5 patients with isolated major bronchial injuries between 2004-2016 were included in this study. The demographic data including the mode of injury, early or delayed diagnosis, clinical features, radiological findings, bronchoscopic findings and surgical repair were compiled. The clinical data like mode of trauma, history of cough, dyspnoea, haemoptysis and fever were noted from the medical records. Injury Severity Score (ISS) of any of these cases was not mentioned in their medical records and hence not reported in this study. The detailed radiological, bronchoscopic findings and the surgical treatment rendered were also noted from the records.

\section{Case 1}

A 20 year old male sustained blunt trauma chest by getting buried in mud. He was admitted in the emergency with respiratory distress and surgical emphysema. Chest X-Ray film had shown a right pneumothorax (Figure 1), total collapse and descent of right lung. Intercostal drain in right chest was inserted for pneumothorax. There was major air leak from the chest tube and lung collapse persisted despite a thoracostomy tube. Patient was restless for which NCCT head was done to rule out head injury. NCCT head was essentially normal. 


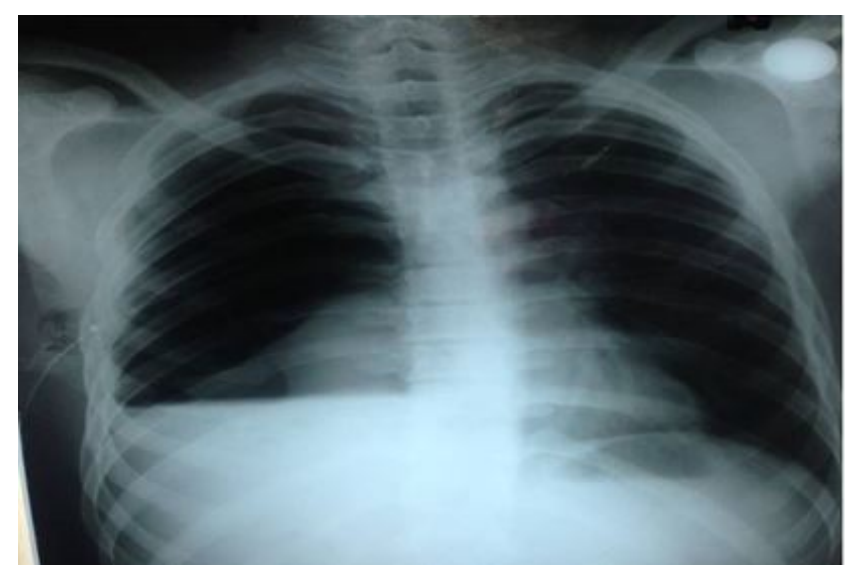

Figure 1: Chest X-Ray film had shown a right pneumothorax.

Due to hypoxia patient general condition was deteriorating as he was unable to maintain the oxygen saturation due to major air leak from chest tube. After 2 days thoracic surgery consultation was taken in view of the continuous major air leak from chest tube. A major airway injury was suspected and patient was shifted to emergency operation theatre for bronchoscopy and emergency exploration. Flexible bronchoscopy revealed complete transection of the right main stem bronchus. Anaesthetist tried to secure the airway by negotiating a single lumen endotracheal tube into the left bronchus over the bronchoscope but failed. Right thoracotomy was undertaken in emergency operation theatre. There was complete transaction of right main bronchus with continuous major air leak from the transection site. Endotracheal tube was directed into the left main bronchus by the surgeon and restoration of the right main bronchial lumen with carina was done in single layer with interrupted sutures using 3-0 vicryl (polyglactin) half circle round body needle absorbable suture material. The repair was covered with a pleural flap and lung expanded completely. The chest was closed over apical and basal pleural drains. Patient was not extubated and he was shifted to ICU for elective ventilation after surgery. Post-operative period was uneventful and he was discharged after two weeks of surgery. Follow up bronchoscopy after 6 weeks was normal.

\section{Case 2}

A 45 years old male sustained blunt trauma chest on left side in a road side accident and was admitted with respiratory distress in our emergency. The exact mode of injury was not reported in the medical records of the patient. A chest X-ray had shown partial lung collapse and pneumothorax on left side for which intercostal drain was put and patient improved. The drain was removed after 10 days as there was no air leak and drainage fluid from the tube and patient was discharged. After two weeks patient was again admitted with left side chest pain and progressive dyspnoea. Breath sounds on left side were absent. A repeat chest X-Ray film had shown complete radio-opacification of the left hemithorax and mediastinal shift to left Side (Figure 2).

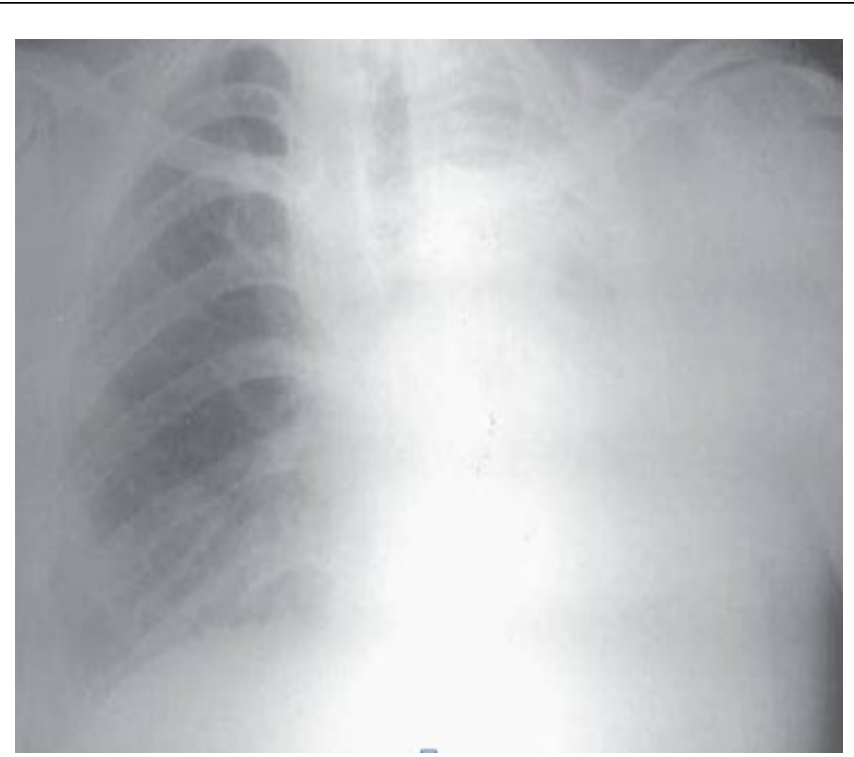

Figure 2: A repeat chest X-Ray film had shown complete radioopacification of the left hemithorax and mediastinal shift to left Side.

Flexible bronchoscopy revealed that the left main bronchus tapered to a point $2 \mathrm{~cm}$ from the carina. CECT chest showed complete cut off of the left main bronchus $2 \mathrm{~cm}$ distal to carina. Left thoracotomy was undertaken in elective operation theatre. Dense adhesions obliterated the aorto-pulmonary window and separated the blind ends of the avulsed left main bronchus $2 \mathrm{~cm}$ from carina. The lung was filled with mucus. Both the ends of the avulsed main bronchus were dissected out carefully and the fibrosed tissue was removed. The left lung expansion before restoration of the bronchial continuity was ensured with a separate $5 \mathrm{~mm}$ internal diameter endotracheal tube into the distal bronchus and slow ventilation by a separate anaesthesia circuit. The restoration of bronchial continuity was done in single layer with interrupted sutures by absorbable 3-0 vicryl (polyglactin) half circle round body needle suture material. The repair was covered with a pleural flap. The lung expanded completely. Chest was closed over apical and basal chest drains. Postoperative recovery was uneventful and the patient was discharged after 14 days. Follow up bronchoscopy after 6 weeks was normal.

\section{Case 3}

A 19 year old male was referred by a private practitioner in pulmonary medicine department of our hospital for the management of persistent right sided pyopneumothorax, and completely collapsed right lung. Patient revealed history of blunt trauma chest by overturning of a moving three wheeler 3 weeks ago following which he was taken to a periphery hospital. An intercostal chest drain was inserted for hydro pneumothorax and collapsed lung by the private practitioner. Clinically breath sounds on the right side were absent. A chest X-Ray film had shown total collapse and descent of right lung with hydro pneumothorax. CECT chest showed complete transaction of right main bronchus, fallen lung sign and hydro pneumothorax with fluid level (Figures 3 and 4). 
Citation: Dalal AK, Dalal UR, Saini V, Kapoor D (2017) Isolated Bronchial Injury: A Diagnostic and Management Challenge. J Surg Anesth 1: 106.

Page 3 of 8

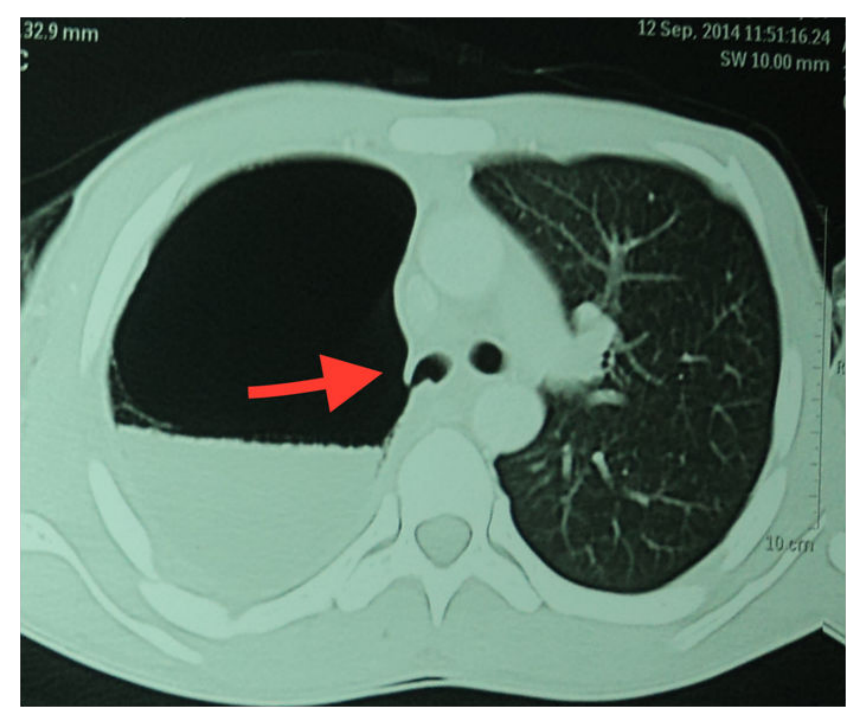

Figure 3: CECT chest showed complete transaction of right main bronchus.

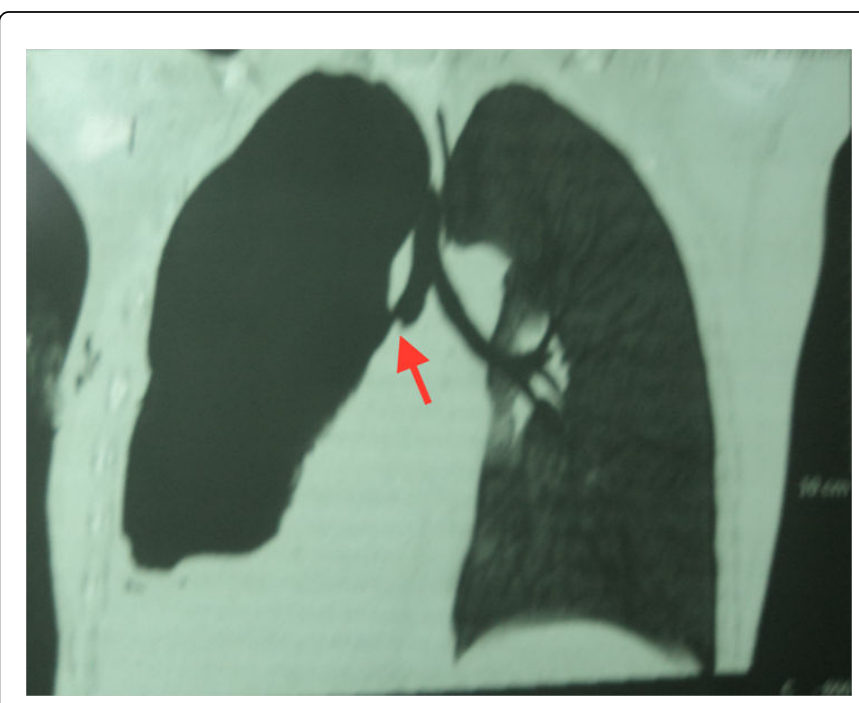

Figure 4: Fallen lung sign and hydro pneumothorax with fluid level.

At flexible bronchoscopy, the scope entered into infected empyema cavity immediately after carina. There was granulation tissue at the transected margins (Figure 5).

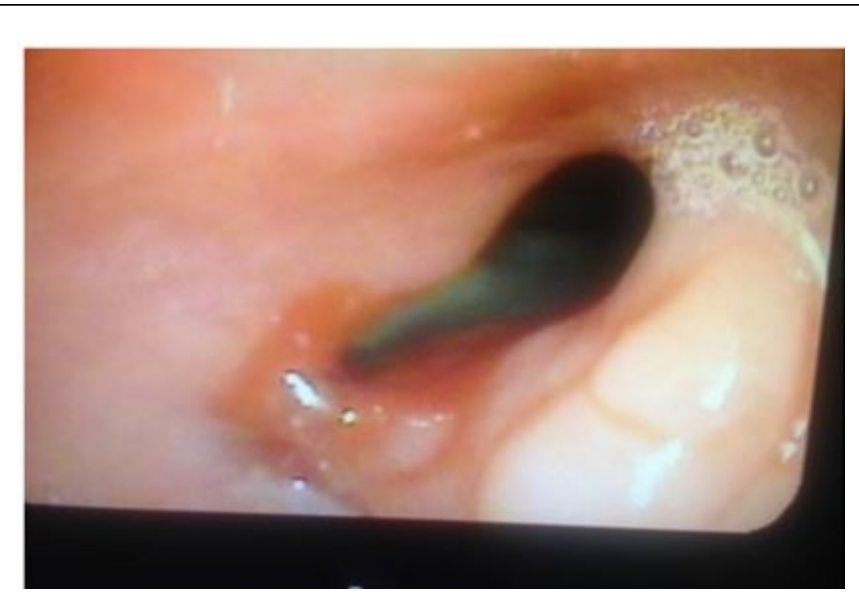

Figure 5: granulation tissue at the transected margins.

On right thoracotomy the operative findings were: complete transection of right main bronchus with granulation tissue on the edges and the collapsed right lung full of mucus was lying medially towards the diaphragm. With an endotracheal tube of $5 \mathrm{~mm}$ internal diameter into the transacted right bronchus, prior lung expansion was done with a separate anaesthesia circuit. After ensuring normal full lung expansion, the restoration of the continuity of right main bronchus with carina was done in single layer with interrupted sutures by using absorbable 3-0 vicryl (polyglactin) half circle round body needle suture and the repair was covered with a pleural flap. Chest was closed over apical and basal intercostal drains in the pleural cavity. Patient was discharged after 3 weeks. Bronchoscopy done after 6 weeks showed healthy suture line.

\section{Case 4}

A 17 year old male (truck cleaner) was admitted in the surgery emergency with respiratory distress and massive surgical emphysema over the chest after getting compressed between window and body of a truck. A chest X-Ray and CT chest film showed massive surgical emphysema bilateral pneumothorax and partially collapsed right lung (Figure 6). 


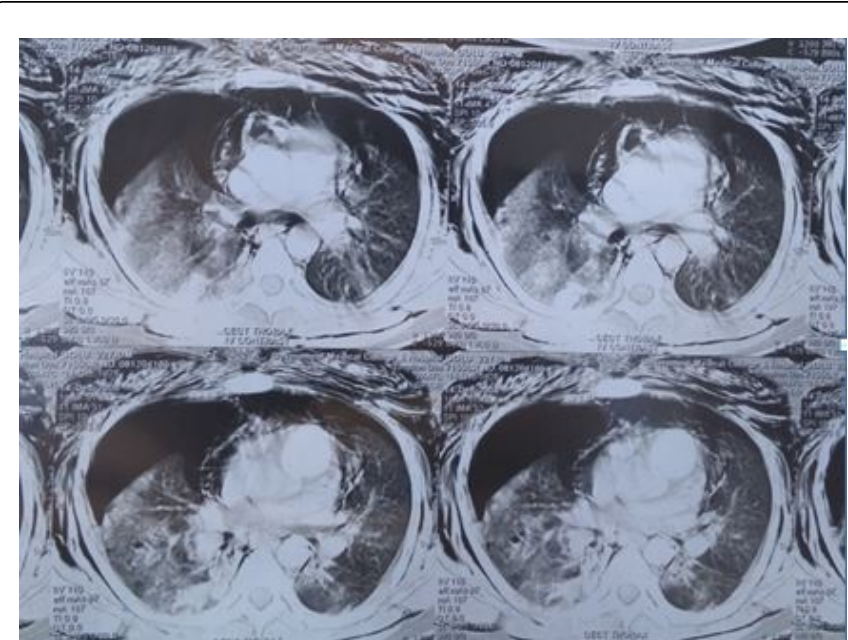

Figure 6: A chest X-Ray and CT chest film showed massive surgical emphysema bilateral pneumothorax and partially collapsed right lung.

Lung failed to expand even after intercostal thoracostomy tube drainage and there was major, continuous air leak from the chest tube. Patient was restless and was not maintaining oxygen saturation. The flexible bronchoscopy had shown a $3 \mathrm{~cm}$ linear tear in the membranous portion of the bronchus intermedius on right side. Emergency thoracotomy on the same day was undertaken and repair of the tear was done in single layer with interrupted sutures using 3-0 vicryl. (polygalactin) half circle round body suture material. The lung fully expanded after repair. Chest was closed over apical \& basal drains in the pleural cavity. Patient had uneventful recovery and was discharged after 2 weeks. Follow up bronchoscopy was normal.

\section{Case 5}

A 20 year old male was admitted with left haemopneumothorax and respiratory distress after blunt trauma chest. Intercostal thoracostomy tube drainage was done in emergency. Lung expanded partially but significant air leak continued till 3 weeks and patient developed empyema. Bronchoscopy was not done in this case due to technical reason. Left thoracotomy was done in elective operation theatre. The repair of a $3 \mathrm{~cm}$ longitudinal rent in lingular lobe bronchus was done in single layer by interrupted sutures using 3-0 vicryl (polyglactin) half circle round body needle suture. Chest was closed over apical and basal intercostal pleural drains. Post-operative period was uneventful and patient was discharged after 10 days.

\section{Results}

During the study period a total of 5 cases of isolated blunt bronchial trauma were diagnosed. All were male patients. The age ranged from 17-45 years. There were three main stem bronchial transection injuries (two cases of right main stem bronchus and one case of left main stem bronchus) and two lobar bronchial injuries (bronchus intermedius right side and lingular lobe bronchus on left side). It was complete transverse tear in all three cases of main bronchus injuries and linear tear in two cases of lobar bronchus injury. One case of right main stem bronchus transection, presented early in our surgery emergency, however, exact diagnosis was estabilished after $48 \mathrm{~h}$ of the admission as patient was being managed initially with provisional diagnosis of head injury. Another patient with right main bronchial transection was treated in a private hospital with right sided intercostal tube drainage for haemo-pneumothorax sustained after blunt trauma chest. He was referred by a private practitioner in the pulmonary medicine department of our hospital after 3 weeks with intercostal drain in-situ for non-expanding lung and empyema right hemi thorax. There was one patient of left main stem bronchial injury after blunt trauma chest resulting in complete stenosis of the left main bronchus after 3 weeks of injury and diagnosis was delayed. Out of two cases of lobar bronchial injuries, in one patient there was injury of the right side middle lobe bronchus which was diagnosed and repaired in $6 \mathrm{~h}$ of admission and in another patient there was lingular lobe bronchial injury which was repaired after 3 weeks due to delay in diagnosis. The pre-operative diagnosis of bronchial injury was made on the basis of medical history, clinical, radiological and bronchoscopic examinations. Flexible bronchoscopy was done in 4 cases. Primary repair was done in 2 cases and delayed repair was done in 3 cases. Two patients were operated within $72 \mathrm{~h}$ of the injury and primary repair or restoration of airway continuity was established. Delayed repair was done in three patients (two of the main stem bronchi, one on each side and in one case of lingular lobe bronchus). In all 3 cases of complete main stem bronchial transection, it was possible to restore the continuity of airway successfully. In two cases of linear injury of lobar bronchi, repair of the injured segment was successful. Repair of the transected bronchus or rent in the bronchus was done in single layer with interrupted sutures using absorbable 3-0 vicryl (polyglactin) round body needle sutures in all cases of this study. The repair was covered with pleural flaps only in main bronchial transection cases. In all cases chest was closed over apical and basal pleural drains. We do not use posterior mediastinum drains routinely and hence in none of the cases of this study posterior mediastinum drainage was done. Fiberoptic bronchoscopy was not used routinely in post-operative period to clear the secretions but it was done after six weeks to check the repair site. There was no mortality in this study. All 5 patients recovered completely restoring normal pulmonary functions. The clinical profile, radiological, bronchoscopic and surgical findings are given the Table 1.

\begin{tabular}{|c|c|c|c|c|c|c|c|c|c|c|}
\hline $\begin{array}{l}\text { S. } \\
\text { No. }\end{array}$ & $\begin{array}{l}\text { Age/Se } \\
x\end{array}$ & $\begin{array}{l}\text { Trauma } \\
\text { type }\end{array}$ & $\begin{array}{l}\text { Injury } \\
\text { side }\end{array}$ & Clinical symptoms & Radiology & $\begin{array}{l}\text { Bronchosco } \\
\text { py }\end{array}$ & $\begin{array}{l}\text { Diagnostic } \\
\text { delay }\end{array}$ & Operation & $\begin{array}{l}\text { Total hospital } \\
\text { stay }\end{array}$ & Outcome \\
\hline 1 & $20 \mathrm{M}$ & Blunt & RMB & $\begin{array}{l}\text { Respiratory distress, } \\
\text { major air leak from } \\
\text { ICD, Surgical } \\
\text { emphysema }\end{array}$ & $\begin{array}{l}\text { CXR- } \\
\text { collapse } \\
\text { lung, } \\
\text { pneumothor } \\
\text { ax }\end{array}$ & $\begin{array}{l}\text { Complete } \\
\text { transection of } \\
\text { RMB at } \\
\text { carina }\end{array}$ & $72 \mathrm{~h}$ & $\begin{array}{l}\text { Right } \\
\text { thoracotomy } \\
\& \\
\text { reconstrction }\end{array}$ & 3 weeks & Survived \\
\hline & & & $\begin{array}{l}\text { Complete } \\
\text { trasaction at } \\
\text { carina }\end{array}$ & & & & & & & \\
\hline
\end{tabular}




\begin{tabular}{|c|c|c|c|c|c|c|c|c|c|c|}
\hline 2 & $45 \mathrm{M}$ & Blunt & LMB & $\begin{array}{l}\text { Progressive } \\
\text { dyspnoea, left sided } \\
\text { chest pain }\end{array}$ & CXR- & $\begin{array}{l}\text { Complete } \\
\text { obliteration of } \\
\text { left main } \\
\text { bronchus } 2 \\
\mathrm{~cm} \text { from } \\
\text { carina }\end{array}$ & 8 weeks & $\begin{array}{l}\text { Left } \\
\text { thoracotomy, } \\
\text { reconstructio } \\
\mathrm{n} \text { of LMB }\end{array}$ & 4 weeks & Survived \\
\hline & & & & & $\begin{array}{l}\text { CT chest- } \\
\text { LMB } \\
\text { complete } \\
\text { transection }\end{array}$ & & & & & \\
\hline 3 & $19 \mathrm{M}$ & Blunt & RMB & $\begin{array}{l}\text { Cough, fever, } \\
\text { progressive } \\
\text { dyspnoea, major air } \\
\text { leak from ICD }\end{array}$ & $\begin{array}{l}\text { CXR-Right } \\
\text { hyderopneu } \\
\text { mothorax, } \\
\text { CT chest- } \\
\text { Right main } \\
\text { bronchus } \\
\text { complete } \\
\text { transection,f } \\
\text { allen lung } \\
\text { sign. }\end{array}$ & $\begin{array}{l}\text { Complete } \\
\text { transection of } \\
\text { RMB }\end{array}$ & 3 weeks & $\begin{array}{l}\text { Right } \\
\text { thoracotomy } \\
\text { \& } \\
\text { reconstrction }\end{array}$ & 3 weeks & Survived \\
\hline 4 & $17 \mathrm{M}$ & Blunt & $\begin{array}{l}\text { Right lobar } \\
\text { bronchus } \\
\text { tear }\end{array}$ & $\begin{array}{l}\text { Cough, } \\
\text { dyspnoea,continous } \\
\text { major air leak from } \\
\text { ICD, Surgical } \\
\text { emphysema }\end{array}$ & $\begin{array}{l}\text { CXR \& CT } \\
\text { pneumothor } \\
\text { ax \& \& } \\
\text { collapse } \\
\text { lung }\end{array}$ & $\begin{array}{l}\text { Longitudinal } \\
\text { tear in } \\
\text { bronchus } \\
\text { intermedius }\end{array}$ & $2 \mathrm{~h}$ & $\begin{array}{l}\text { Right } \\
\text { thoracotomy } \\
\& \text { primary } \\
\text { closure of } \\
\text { leak/rent }\end{array}$ & 2 weeks & Survived \\
\hline 5 & $20 \mathrm{M}$ & Blunt & $\begin{array}{l}\text { Left lobar } \\
\text { bronchus } \\
\text { tear }\end{array}$ & $\begin{array}{ll}\text { Cough } & \text { major air } \\
\text { leak, } & \text { empyema } \\
\text { chest } & \end{array}$ & $\begin{array}{l}\text { CXR \& CT } \\
\text { pneumothor } \\
\text { ax \& } \\
\text { collapse } \\
\text { lung }\end{array}$ & Not done & 3 weeks & $\begin{array}{l}\text { Left } \\
\text { thoracotomy } \\
\text { \& repair of } \\
\text { leak. }\end{array}$ & 2 weeks & Survived \\
\hline
\end{tabular}

Table 1: Clinical and management data; RMB: Right main bronchus; LMB: Left main bronchus; ICD-Inter-costal drain; M: Male, CXR: Chest Xray.

\section{Discussion}

Bates stated that a thoracic surgeon in Britain may see two tracheobronchial injuries over 30 years of practice [9]. The frequency of injury rates are as follows: cervical trachea $4 \%$, distal trachea $22 \%$, right main stem bronchus $27 \%$, left proximal main stem bronchus $17 \%$, complex injury of trachea and main stem bronchi are very rare comprising $8 \%$ and lobar orifices $16.8 \%$ blunt bronchial injuries afflict up to $2.8 \%$ of severe blunt chest trauma and are potentially life threatening because of tension pneumothorax, therefore, have the first priority for the treatment in trauma management. Krinitzki reported the first long term survivor in 1927 when trachea-bronchial injuries had been thought to be uniformly fatal [10]. Most of patients die within first few minutes of injury because of inadequate airway, tension pneumothorax and associated injuries. Most frequent topography of the injuries in $47 \%$ of the cases is injury involving the right main bronchus. This is probably due to the major dimension and smaller length of the right main bronchus $[8,11,12]$. The left main stem bronchus is fixed with the major vessels and hence is partially protected, however, because of lack of supporting structures around the right main stem bronchus and heavier right lung (due to the presence of middle lobe) on the shorter right main bronchus, the right main bronchus ruptures more frequently. In our study two were right main stem bronchus injury and one was left main stem bronchus injury. $80 \%$ of the cases of tracheo-bronchial injuries are located within $\pm 2.5 \mathrm{~cm}$ of carina confirming Laplace's law; pressure in the wall of a hollow structure increases with increase in its radius [12]. Three of the five blunt bronchial injuries in this series were within $2.5 \mathrm{~cm}$ of the carina. Equal frequency of right sided and left sided main stem bronchial injuries are reported in the literature [3]. Right sided injuries have higher incidence of associated injuries and they are also detected earlier than the left sided injuries. Bronchial rupture may be transverse from the carina (as it was in our two cases of right bronchial transaction from carina), between the bronchial rings, (as it was in our third case with fracture of the bronchial rings of left main bronchus), longitudinal (as it was seen in our fourth and fifth cases of lobar bronchial tear) or complex. The injury period may be divided into following phases: hematoma formation and development of stricture [13]. Maturation of fibrous stricture and its sequel occur in third or fourth week after injury. Total disruption of a bronchus favours its complete occlusion and begets atelectasis, which is usually sterile and is amenable to surgical repair $[14,15]$. Even if the respiratory tract separates partially or wholly, it may be held together to sustain airway and ventilation through its strong para tracheal connective tissue. The granulation tissue and scar formation result in stricture formation one to four weeks after injury.

Trauma may be trivial but history of compression is suggestive [16]. Several theories have been proposed regarding the mechanism of blunt tracheobronchial disruption $[2,13]$. The first theory states, sudden and forceful antero-posterior compression of the chest causing increase in transverse diameter of the chest which pulls away the two lungs apart in lateral direction with carina and trachea fixed at the spine (crush), avulsing the bronchus. Second theory states, compression of chest and trachea abruptly increasing airway pressure in trachea and larger bronchi resulting in rugged, burst bronchial injury. When the pressure exceeds the elasticity of the tracheobronchial tree, the airway ruptures 
usually at the membranous level. Iatrogenic increase in the airway pressure, rupture the alveoli instead perhaps due to slower increase in pressure. The third proposed mechanism relates to rapid deceleration injuries as some structures are fixed (trachea and carina) and other structures that are not fixed. Shearing forces occur at relatively fixed points such as carina and cricoids cartilage. This mechanism of injury seems to be most logical in blunt trauma victims of motor vehicle injuries or fall of heavy weight on the victim. Our first case sustained right main stem bronchial trisection due to sudden fall of mud over him and in third case right main stem bronchial transection occurred due to overturning of the fast moving three- wheeler, in which he was travelling.

Velly in his series describes critical symptoms in $90 \%$ of the patients who arrived alive to the hospital [7]. Clinical presentation depends on the site and size of the air leak and whether it is communicating with the pleura. In the common communicating type findings are major air leak from the chest tube and despite adequate chest drainage lung fails to expand. Right main stem bronchus injuries have more acute presentation due to higher incidence of associated injuries. Three different clinical patterns are seen in the bronchial injuries. The first pattern is described when the bronchial injury is in communication with the pleural space (thoracic trachea or the bronchial injuries) where dominant clinical features are of tension pneumothorax and major air leaks. In the second type there is no communication with the pleural space and mostly patient will present with cough, haemoptysis, dyspnoea, pneumo-mediastinum and subcutaneous emphysema. The third type of clinical pattern is incidental diagnosis of an old bronchial injury later on or even years after trauma (chronic presentation) $[17,18]$. In the chronic type, patient presents with progressive exertional dyspnoea, stridor and complete atelectasis of distal lung. On bronchoscopy, we usually find a granulation tissue obtruding the bronchus. Later on the lung gets progressively filled by mucus.

The clinical manifestations in tracheobronchial injuries are protean and symptoms, signs and investigations can all be non-specific. Ten percent of the cases may have little evidence of thoracic mischief and in only one third of the cases a definitive diagnosis is made within $24 \mathrm{~h}$ [13-15]. The diagnosis is suspected on clinical grounds either because they are critically ill or fail to respond to the treatment aided by radiological findings and bronchoscopy examination. Kumpe in 1970 described the "falling lung sign" that is pathognomic of total rupture of main bronchus and/or rib fractures $[19,20]$. Now-a-days CECT thorax is an important diagnostic aid and is the investigation of choice in chest injuries as it is possible to make a three dimensional reconstruction of the tracheobronchial tree along with "falling lung sign", absent hilum or a collapsing of lung away from the hilus towards the diaphragm $[21,22]$. In addition, CECT chest may also reveal other associated injuries, mediastinal air separation of trachea-bronchial air column, respiratory tract deviation or specific location of the tear. However, CECT is contraindicated in hemodynamically unstable patients and sometimes the injuries of segmental bronchus may be missed even with CECT or bronchoscopy due to a collapsed lung covering the rent. Although a negative CT does not obviate the need for broncoscopy, however, CT bronchography or virtual bronchoscopy may be helpful in localising the injury site [23].

Although CECT is the investigation of choice in chest injuries but the corner-stone for the definitive diagnosis of an airway injury is bronchoscopy and should be done at the earliest even in mere suspicion of the airway injury. In addition to diagnosis, bronchoscopy aids in evaluation of the topography, the extension and depth of the tear and its margin status [22-25]. It is also therapeutic in initial stages as it can assist in the oral intubation, positioning of the cuff distal to the injury in case of a proximal lesion and selective bronchial intubation [20]. Bronchoscopy should be performed under operating room conditions [21]. Fiberoptic bronchoscopy can be done easily and quickly even in accompanying neck, head or cervical spine injuries. If done in an intubated patient, the endotracheal tube must be carefully withdrawn or the proximal tracheal injury may be missed.

\section{Management}

Airway injuries may escape diagnosis due to distal intubation done to stabilize the patient with multiple injuries or they may not be clinically suspected altogether initially. Minor leaks, only mucosal defects, or a linear tear involving less than one third diameter of airway where lung expansion is full without persistent air leak may not require any surgical repair and heal with conservative management only without any negative sequel.

Management of injuries of distal trachea, carina and proximal main stem bronchi is extremely challenging. Immediate management should be directed towards the airway management. Respiratory distress may be relieved by intubation or by inserting a rigid bronchoscope which in addition to diagnosis may provide temporary airway and facilitates selective bronchial intubation [23-25]. Team approach between the surgeon and anaesthetist is crucial for the successful outcome. The most common cause for respiratory distress is tension pneumothorax; therefore, an intercostal chest drain should be placed quickly. Continued major air leak, inability to maintain saturation despite of oxygenation should raise the suspicion of major airway injury and emergency thoracotomy should be planned. Suction should never be applied on the thoracostomy tube as it will be further worsen the hypoxia. Positive pressure ventilation is of little use in major bronchial disruptions. The use of double-lumen endotracheal tube for anaesthesia should be avoided because of its rigidity and larger size as it may increase the size of the tear. A long single-lumen endotracheal tube must be placed either beyond the injury location or in the normal uninjured main bronchus to ensure effective single lung ventilation. Endobronchial blockers or double-lumen tube may also be used in selective cases who are haemodynamically stable or in lobar/segmental bronchial injuries. In some situations even the sterile tubes may be placed from the operative field. In our first case oral intubation by single lumen endotracheal tube into the left main bronchus was assisted by the surgeon during surgery and still there was major air leak in the operative field. Ventilation may also be maintained by high frequency jet ventilation during reconstruction of the airway. Cardiopulmonary bypass (CPB) is never necessary for the management of isolated airway injury unless accompanied by heart and great vessels injuries. CPB may exacerbate intra-cerebral or intraabdominal haemorrhage and may cause ARDS.

In some of the cases with moderate lesion, non-operative treatment may be undertaken if the patient is clinically stable especially in high risk cases. The maximum tracheal injury length which can be treated conservatively is $4 \mathrm{~cm}$ or less but it is not the only factor to decide conservative over surgical treatment. Conservative management with antibiotics, intubation and intercostal chest drain may be undertaken for shorter lacerations which do not involve full thickness of wall. The other criteria for conservative treatment are: vitals are stable, no open tracheal injury, peripheral tear, those measuring less than one third the diameter of injured bronchus and no other organ or major vessel injury. Mucosal defects where the lung expansion is full without a 
persistent major air leak, may heal with conservative treatment, but outcome may be uncertain as it heals with a granulation tissue and a stricture/stenosis may result which may require intervention later on [26-28]. Griffith demonstrated the possibility of secondary repair in 1948 although functional success becomes unpredictable with time [26]. Fibrosis and entrapment of the lung parenchyma may result later on requiring resection surgery.

The traditional treatment for major airway injuries has been surgery. Early primary repair, first performed successfully by Sanger in 194, eliminates stricture formation and is the procedure of choice [29]. Repair of small bronchi is also successful, however, extensive damage may necessitate resection. Indications for surgery are: tears equal to or more than $2 \mathrm{~cm}$, more than one third of the circumference, full wall thickness tear, injury of the carina or paracarinal region, failure of the chest-tube, persistent pneumothorax with major air leaks, persistent lung collapse and associated oesophageal injuries or prolapsed of oesophageal wall.

The decision to operate and the choice of operation will be influenced by the capabilities of hospital, monitoring devices, diagnostic facilities and treatment expertise. Right postero-lateral thoracotomy at the fifth intercostal space can allow excellent exposure of the thoracic trachea, carina and right main bronchus. Trimming of the border of the injury and direct suture repair should be done in single layer with interrupted absorbable 3-0 or 4-0 sutures as per the diameter of the injured bronchus. Non absorbable suture should not be used as it may cause tissue granuloma and may erode into the lumen. Repair of the smaller bronchi is rewarding. In case of impossibility of a primary reconstruction, a sleeve anastomosis or pulmonary resection in case of extensive laceration may be undertaken. In the present series no resection procedure was required. In post-operative period, mechanical ventilation is not required, however, if the patient is not extubated, operation may be concluded with single-lumen endotracheal tube for elective ventilation, good pulmonary toilette and check bronchoscopy. If long term ventilation is required, tracheostomy may be required after the surgery.

Complications of the repair are mostly related to the anastomosis [30,31]. Early complications are anastomotic leak or fistula (tracheovascular or tracheo-oesophageal). Anastomotic leak or primary injury heals with granulation tissue and scar contracture. Subsequent stricture formation usually develops 1 to 4 weeks after injury or dehiscence of the suture line [29]. Late complications include cicatrial retraction at suture line and stenosis which may require endoscopic dilatation or re-intervention later on.

\section{Conclusion}

Isolated blunt bronchial trauma is a rare but serious and potentially fatal injury. Diagnosis is difficult and a missed diagnosis is common due to non specific clinical presentation. Therefore, in blunt chest trauma prompt recognition of the airway injury is crucial for early surgical intervention. Important factor for determining the outcome in bronchial trauma is the presence of other associated injuries. Prompt airway management and early repair can greatly improve the chances of restoring normal pulmonary functions.

\section{References}

1. Bertelsen S, Howitz P (1972) Injuries of the trachea and bronchi. Thorax 27: 188-194.
2. Kirsch MM, Orringer MB, Behrendt DM, Sloan H (1976) Management of tracheobronchial disruption secondary to non-penetrating trauma. Ann Thorac Surg 22: 93-101.

3. Roxburgh JC (1987) Ruprure of tracheobronchial tree. Thorax 42: 681-688.

4. Ramzy AI, Rodrgue ZA, Tumey SZ (1988) Management of major tracheobronchial ruptures in patients with multiple system trauma. J Trauma 28: 1353-1357.

5. Pasic M, Ewert R, Engel M, Franz N, Borges P, et al. (2000) Aortic rupture and concomitant transection of left bronchus after blunt chest trauma. Chest 117: 1508-1510.

6. Karmy, Jones R, Wood RD (2007) Traumatic injuries to trachea and bronchus. Thorac Surg Clin 17: 35-46.

7. Kiser AC, O'Brein SM, Detterback FC (2001) Blunt tracheobronchial injuries: treatment and outcomes. Ann Thorac Surg 71: 2059-2065.

8. Velly JF, Martigue C, Mordeau, Dubeez J, Kerdi S, et al. (1991) Post traumatic tracheobronchial lesions. A follow-up study of 47 cases. Eur J Cardiothorac Surg 5: 352-355.

9. Bates M (2007) Rupture of the bronchus. In Williams WG, Smith RE. eds. Trauma of the chest (the Coventry conference) Bristol, England: John Wright and Sons 142-150.

10. Krinitzki SI (1927) Zur kasuistik einer vollstandigen zerrei Bung des rechten luftrohenastes. Virchow Archiv 266: 815-819.

11. Rossabach MM, Johnson SB, Gomez MA, Sako EY, Miller OL, et al. (1998) Management of major tracheobronchial injuries: a 28 -year experience. Ann Thorac Surg 65: 182-186.

12. Buhr J, Kim C, Schafer A, Henneking K (1996) Traumatic bronchus rupture- pathogenesis, surgical and postoperative management. Chirurg 67: 277-279.

13. Burke JF (1962) Early diagnosis of early rupture of the bronchus. JAMA 181: 682-686.

14. Mahaffe DE, Greech O, Boren HG, DeBakey ME (1947) Traumatic rupture of the bronchus successfully repaired eleven years after injury. J Thorac Surg 16: 571-583.

15. Deslauriers J, Beaulieu M, Archambault G, LaForge J, Bernier R (1982) Diagnosis and long-term follow-up of major bronchial disruptions due to non-penetrating trauma. Ann Thorac Surg 33: 32-39.

16. Reddy S, Davierwala P, Kumar P, Thakur N, Babu P, et al. (2002) Bronchial transaction resulting from trivial blunt chest trauma. Ann Thorac Surg 73: 1948-1949.

17. Richardson JD, Miller FB, Camillo EH, Spain DA (1996) Complex thoracic injuries. Surg Clin North Am 76: 725-748.

18. Ozcelik C, Onat S, Bayar ES (2004) Combined late diagnosed right main bronchial disruption and chylothorax from blunt chest trauma. Ann Thorac Surg 78: e61-e62.

19. Kumpe DA, Oh KS, Wyman SM (1970) A characteristic pulmonary finding in unilateral complete bronchial transaction. AJR Am J Roentgenol 110: 704-706.

20. Oh KS, Fleichner FG, Wymen SM (1969) Characteristic pulmonary finding in traumatic complete transection of a main-stem bronchus. Radiology 92: 371-372.

21. Wintermark M, Schnyder P, Wicky S (2001) Blunt traumatic rupture of a mainstem bronchus: spiral CT demonstration of the "fallen lung" sign. Eur Radiol 11: 409-411.

22. Griffith JL (1949) Fracture of the bronchus. Thorax 4: 105-109.

23. Grover FL, Ellestad C, Arom KV, Root HD, Cruz AB, et al. (1979) Diagnosis and management of major tracheobronchial injuries. Ann Thorac Surg 28: 384-391.

24. Deslauriers J, Beaulien M, Arvhambautt G, La Forge J, Bernier R (1982) Diagnosis and long term follow-up of major bronchial disruption due to non penetrating trauma. Ann Thorac Surg 33: 32-39.

25. Jones CM, Athanasion T (2005) Is virtual bronchioscopy an efficient diagnostic tool for the thoracic surgeon. Ann Thorac Surg 79: 365-374. 
Citation: Dalal AK, Dalal UR, Saini V, Kapoor D (2017) Isolated Bronchial Injury: A Diagnostic and Management Challenge. J Surg Anesth 1: 106.

Page 8 of 8

26. Gómez-Caro A, Ausín P, Moradiellos FJ, Díaz-Hellín V, Larrú E, et al (2006) Role of conservative medical management of tracheobronchia injuries. J Trauma 61: 1426-1435.

27. Urchel HC, Razzuk MA (1973) Management of acute traumatic injuries of tracheobronchal tree. Surg Gynacol Obstet 136: 113-117.

28. Gabor S, Rennez H, Pinter H, Sankin O, Maier A, et al. (2001) Indications for surgery in tracheobronchial ruptures. Eur J Cardiothorac Surg 20: 399-404.
29. Sabger PW (1945) Evacuation hospital experiences with war wounds and injuries of the chest. Ann Surg 122: 147-162.

30. Tashkinen SO, Salo JA, Halttunen PE, Sovijärvi AR (1989) Tracheobronchial rupture due to blunt trauma: a follow-up study. Ann Thorac Surg 48: 846-849.

31. Wright CD, Grillo HC, Wain JC, Wong DR, Donahue DM, et al. (2004) Anastomotic complications after tracheal resection: prognostic factors and management. J Thorac Cardiovasc Surg 128: 731-739. 